OPEN ACCESS

Edited by:

Michel Prudent,

Transfusion Interrégionale CRS,

Switzerland

Reviewed by:

Lorenzo Alberio,

Centre Hospitalier Universitaire

Vaudois (CHUV), Switzerland

Peter Schubert,

Canadian Blood Services, Canada

*Correspondence:

Thomas Thiele

thielet@uni-greifswald.de

Specialty section:

This article was submitted

to Hematology,

a section of the journal

Frontiers in Medicine

Received: 11 December 2017

Accepted: 18 January 2018

Published: 05 February 2018

Citation:

Handtke S, Steil L, Greinacher A and

Thiele T (2018) Toward the Relevance of Platelet Subpopulations for

Transfusion Medicine.

Front. Med. 5:17.

doi: 10.3389/fmed.2018.00017

\section{Toward the Relevance of Platelet Subpopulations for Transfusion Medicine}

\author{
Stefan Handtke ${ }^{1}$, Leif Steil ${ }^{2}$, Andreas Greinacher ${ }^{1}$ and Thomas Thiele ${ }^{1 *}$ \\ ${ }^{1}$ Institut für Immunologie und Transfusionsmedizin, Greifswald, Germany, ${ }^{2}$ Interfakultäres Institut für Funktionelle \\ Genomforschung, Greifswald, Germany
}

Circulating platelets consist of subpopulations with different age, maturation state and size. In this review, we address the association between platelet size and platelet function and summarize the current knowledge on platelet subpopulations including reticulated platelets, procoagulant platelets and platelets exposing signals to mediate their clearance. Thereby, we emphasize the impact of platelet turnover as an important condition for platelet production in vivo. Understanding of the features that characterize platelet subpopulations is very relevant for the methods of platelet concentrate production, which may enrich or deplete particular platelet subpopulations. Moreover, the concept of platelet size being associated with platelet function may be attractive for transfusion medicine as it holds the perspective to separate platelet subpopulations with specific functional capabilities.

Keywords: platelet subpopulation, platelet size, platelet turnover, platelet clearance, platelet maturation

\section{INTRODUCTION}

Platelets recognize vessel damage, trigger coagulation and enhance clot formation at the site of injury (1). Beyond hemostasis, platelets also act as mediators in immunity and inflammation (2-5).

Circulating platelets differ in age, maturation state, or density. An obvious physical feature of platelets is their size, which can vary substantially among platelets of one individual. It was an early concept, that large platelets represent a rather young and reactive platelet subpopulation (6). Later, this concept was abandoned when consecutive experiments demonstrated no clear correlation between platelet size and age $(7,8)$.

The observation that some platelets have particular procoagulant capabilities led to the concept of platelet subpopulations with different biological functions (9). Other examples for platelet subpopulations are reticulated (rather young) platelets and platelets exposing signals mediating their clearance from the circulation (rather old platelets). It is conceivable albeit unclear, whether other platelet subpopulations exist which play a more pronounced role in immunological or inflammatory processes, e.g. by expression of CD40 or release of CD40L $(10,11)$.

Epidemiological studies found an association between an increased platelet size and thrombotic outcomes in patients with cardiovascular disease (12) resulting in a revival of the "old" hypothesis of an association between a larger platelet size and enhanced platelet function in hemostasis.

Clarifying the hypothesis of different biological features of platelet subpopulations is potentially relevant for transfusion medicine. Enrichment of distinct platelet subpopulations in platelet concentrates (PCs) during production may modulate the biological effects of PCs. 
In this review, we summarize the current knowledge on platelet subpopulations with a special emphasis on platelet size, its association with platelet function and the impact of platelet turnover on platelet production.

\section{SIZE AS A PLATELET CHARACTERISTIC}

\section{Platelet Formation, Turnover, and their Role for Platelet Size}

Platelet size is genetically determined and relatively stable over the lifetime in healthy individuals. Genome wide association studies in healthy subjects identified several genes associated with platelet size (13-18).

Under steady-state conditions, platelets are generated from megakaryocytes in the bone marrow after stimulation with thrombopoietin. The amount of circulating thrombopoietin is regulated by the mass of circulating platelets. They bind thrombopoietin, providing a negative feedback mechanism to control thrombopoiesis (19). In mice, thrombopoietin administration increases platelet size (20) whereas in humans the opposite seems to be the case (21).

In the bone marrow, preplatelet intermediates are formed as extensions of elongated megakaryocyte-pseudopodia and released into the sinusoidal blood vessels $(22,23)$. Glycoprotein Ib mediates transmigration of megakaryocytes into the sinusoids via the small GTPases Cdc42 and RhoA (24). Preplatelets convert into barbell-shaped proplatelets that form platelets $(23,25)$ mediated by integrin $\alpha$ IIb $\beta I I I$ signaling (26). Platelet size is established during the formation of barbell proplatelets from circular preplatelets and limited by microtubule bundling, elastic bending, and actin-myosin-spectrin cortex forces (27).

Thrombopoiesis in the bone marrow is spatially regulated (28) but platelet maturation does not end in the bone marrow. Preplatelets are also formed from proplatelets in the circulation (29) and can maturate in the lungs (30).

In vivo, the mechanisms of proplatelet formation are very dynamic and influenced by platelet turnover (31). In case of inflammation an alternative pathway of platelet production can occur. Nishimura et al. found that increased serum levels of the inflammatory cytokine IL- $1 \alpha$ induce platelet release by the rupture of megakaryocytes as a distinct mechanism in the absence of elevated thrombopoietin (32). Via this mechanism, larger platelets are produced than in thrombopoietin-stimulated megakaryocytes in mice.

We have established a model of enhanced platelet production in healthy volunteers using platelet apheresis showing that platelet apheresis stimulated platelet production leads to reversible changes in the platelet proteome (33). This further indicates an impact of platelet turnover on the phenotype of circulating human platelets.

\section{Platelet Size and Function during Steady- State Platelet Production}

Most studies identified large platelets as a subpopulation with a higher prohemostatic capacity, if generated under steady state. However, it is still debated whether a larger size alone contributes to this higher capacity (34), or if there are specific features in large platelets which over-proportionally increase their prohemostatic potential. Table 1 provides an overview of functional comparisons between large and small human platelets. The majority of experiments included adjustments for cell size, suggesting a hyperproportional prohemostatic capacity of large platelets.

Steady-state large platelets have a higher capacity for glucose metabolism, resistance to osmotic shock (36), and lipid peroxidation (38). They aggregate faster and release more ATP and alpha granule proteins $(34,37)$, contain more fibrinogen, and serotonin (40), and express more human leukocyte antigen-I molecules (41) and membrane glycoproteins (43).

Platelets synthesize proteins (50) and large platelets have more ribosomes and incorporate more amino acids (35). Probably, large platelets have a higher capacity to translate mRNA. This needs to be demonstrated by future studies, which adequately control for residual leukocytes in the large platelet fraction.

Opper et al. found different patterns of cGMP synthesis and protein phosphorylation patterns after stimulating platelets of different size $(44,46)$, suggesting differences in signal transduction between large and small platelets.

The ability to mobilize $\mathrm{Ca}^{2+}$ in the cytosol is pivotal for platelet activation. $\mathrm{Li}$ et al. showed that the cytosolic $\mathrm{Ca}^{2+}$-concentration is similar in resting large and small platelets, whereas higher amounts of $\mathrm{Ca}^{2+}$ are mobilized by large platelets (45).

Large platelets express more surface-bound fibrinogen, bind more von Willebrand factor, and metabolize more arachidonic acid (39), express more P-selectin, activate more integrin $\alpha \mathrm{IIb} \beta 3$ after ADP-stimulation $(42,47,51)$, and release more thromboxane after collagen- and thrombin-induced aggregation in proportion to platelet size (39).

A recent study indicates that large-size platelets are functionally different compared to small platelets. Brambilla et al. found that large platelets express not only significantly higher amounts of tissue factor and tissue factor mRNA compared to small platelets. Large platelets also expose functionally active tissue factor on their cell membranes whereas the activity of tissue factor in small platelets is almost completely quenched by tissue factor pathway inhibitor (48). These results extent previous findings showing that platelets translate tissue factor (52) and point toward specific roles of large and small platelets in hemostasis.

\section{Platelet Size during Increased Platelet Turnover}

If platelet production is enhanced in healthy humans by application of thrombopoietin, the peripheral platelet concentration increases whereas platelet size measured by the mean platelet volume (MPV) slightly decreases without changes in platelet viability, platelet responsiveness to physiologic agonists, or expression of platelet activation markers (21).

In contrast, disease-related increased platelet turnover is often associated with an increase in platelet size $(6,53)$, e.g., in case of enhanced destruction of platelets by autoantibodies (54-56), during recovery after bone marrow suppression by chemotherapy (49), or in situations with increased consumption in patients with severe arterial disease $(57,58)$. These 
TABLE 1 | Functional characterization of human large and small platelets.

\begin{tabular}{lll}
\hline Reference & Results & Size adjustment \\
& & $\begin{array}{l}\text { Evidence for a hyperproportional } \\
\text { difference between large and } \\
\text { small platelets }\end{array}$
\end{tabular}

\section{Steady-state platelet production}

Booyse et al. (35)

Only large platelets contain ribosomes

Karpatkin (36)

Large platelets: higher glycogen, higher orthophosphate, higher total adenine nucleotide, higher glucogenolysis capacity, higher glycolysis activity, higher protein synthesis, higher glycogen synthesis, higher resistance to osmotic shock

Karpatkin (37)

Large platelets: lag time to aggregation shorter; higher ATP release; following aggregation higher ADP release; higher release of platelet factor 4

Karpatkin and Strick (38)

Large platelets: higher activity of glycolysis enzymes, less lipid peroxidation product, more resistant to lipid peroxidation

Thompson et al. (34)

Large platelets: maximal aggregation after activation by collagen or thrombin increased; contain larger amounts of ATP and beta-thromboglobulin

Jakubowski et al. (39)

\section{Large platelets: release more thromboxane after} collagen or thrombin stimulation

Platelet size correlates with the amount of metabolized arachidonic acid

\begin{tabular}{ll}
\hline Mezzano et al. (40) & $\begin{array}{l}\text { Large platelets: more fibrinogen, more serotonin } \\
\text { and more absolute protein }\end{array}$ \\
\hline Pereira et al. (41) & Large platelets: more P1 ${ }^{\text {a1 }}$ molecules; small \\
& platelets: more HLA-A2 molecules, more total \\
& HLA class I-molecules \\
\hline Frojmovic et al. (42) & Large platelets: more fibrinogen receptor \\
& expressed on membrane when activated; faster \\
& aggregation rate
\end{tabular}

Polanowska-Grabowska et al. (43) Large platelets: faster adhesion to collagen, less sensitive to inhibition by prostacyclin, increased content of glycoprotein la/iia complex

Opper et al. (44)

Large platelets: higher basal level of cgmp, higher cgmp synthesis rate after stimulation with sodium nitroprusside, lower activity of campdependent phosphodiesterases

Li et al. (45)

Large platelets: higher maximal aggregation after stimulation with thrombin, increased ATP secretion, higher degree of calcium mobilization

Opper et al. (46)

Large platelets: higher degree of protein phosphorylation after thrombin stimulation, higher rate of ADP-ribosylation by cholera toxin; small platelets: higher basal phosphorylation levels of several proteins, higher ADP-Ribosylation by pertussis toxin and C3 exoenzyme, higher basal $\mathrm{Ca}^{2+-}$ level

Mangalpally et al. (47)

Large platelets: express more surface-bound fibrinogen, bind more von Willebrand factor after arachidonic acid- or ADP-stimulation, express more P-selectin, more activated glycoprotein iib/ iiia after ADP stimulation; higher proportion of reticulated platelets

Brambilla et al. (48)
Large platelets: contain higher amounts of tissue Not performed factor and tissue factor mrna; mainly large platelets expose functionally active tissue factor
Not performed Yes

Ratios of analytes compared to ratios of Yes

platelet volumes

Not performed

Not applicable

Equal amount of protein extract taken Yes

from large and small platelets

Relative change within each size fraction Yes

(aggregometry); relative comparison of

ATP and beta-thromboglobulin before

and after stimulation

Correlation to MPV No

Not performed

Not applicable

Not performed

Not applicable

Correlation of ratios large/small with size No

ratio large/small

Not performed

Not applicable

Adjustment of protein content and

Yes

platelet size

Relative change within each size fraction Yes

(aggregometry)

Equal amount of protein extract

Yes

taken from large and small platelets

Adjustment to the platelet surface area Yes

(Continued) 
TABLE $1 \mid$ Continued

\begin{tabular}{lll}
\hline Reference & Results & Size adjustment \\
& & $\begin{array}{l}\text { Evidence for a hyperproportional } \\
\text { difference between large and } \\
\text { small platelets }\end{array}$
\end{tabular}

Increased platelet turnover

Balduini et al. (49)
Old platelets: MPV and P-LCR reduced; young platelets: MPV and P-LCR higher compared to old and to control; aggregation response faster in young platelets
Relative change within each size fraction Yes (aggregometry)

MPV, mean platelet volume; P-LCR, platelet large cell ratio; HLA, human leukocyte antigen.

studies suggest that platelet size in disease is regulated by other mechanisms than the ones regulating platelet size during thrombopoietin-mediated megakaryocytopoiesis in healthy volunteers. Severe thrombocytopenia induced by disseminated intravascular coagulation in children is also associated with an increase in platelet size (59). However, in view of the findings of Nishimura et al. (32), this likely results from platelet production by the alternative pathway involving IL- $1 \alpha$ induced fragmentation of megakaryocytes.

\section{Platelet Size and Platelet Age}

The first attempts to characterize young platelets were driven by the hypothesis, that large platelets are considerably younger than small platelets because they are more functionally active $(37,38)$. However, later studies did not reveal a direct relationship between platelet size and age. This was convincingly underscored by an experiment in baboons under conditions of steady-state platelet production. The animals received radioactively labeled methionine being incorporated by megakaryocytes (8). Radioactively labeled platelets were afterwards present in each assessed size fraction of platelets indicating that size and age of platelets do not correlate under steady-state conditions. Also in humans platelet size is likely not strongly associated with platelet age (7). After transfusion of radioactively labeled autologous platelets, the mean survival of a high-density platelet population was shorter than that of platelets with low density. The mean volumes of high- and low-density platelets were not different suggesting that platelet size is unrelated to platelet age under normal conditions, but implicating a role of platelet density for the age of circulating platelets.

\section{Platelet Size as Risk Factor for Adverse Clinical Outcomes}

Epidemiological studies in patients with cardiovascular disease found an association between an increased MPV and a higher prevalence of thromboembolic complications (12, 60-62). An increased platelet size due to increased platelet turnover also correlates with refractoriness to antiplatelet therapy (58) and predicts a higher incidence of adverse outcomes after coronary intervention (63).

It is unclear, whether the increased MPV is the cause or the consequence of an increased risk for thromboembolic outcomes $(60,64)$. An alternative explanation is that individuals with large platelets have per se an increased risk for thrombotic complications because genetic traits have been identified, which are at the same time associated with an increased MPV and an increased risk for cardiovascular disease (65).

An increased MPV also characterizes inherited bleeding disorders with dysfunctional large platelets (66).

\section{PLATELET SUBPOPULATIONS}

\section{Reticulated Platelets}

Ingram et al. first observed a unique population of newly formed platelets soon after the induction of acute blood loss in beagle dogs. They stained platelets with methylene blue and noticed coarse and punctate condensations in platelets similar to those seen in reticulocytes of red cells. Therefore, this platelet fraction was named "reticulated platelets" (67). Later, reticulated platelets were shown to contain more RNA, staining with nucleic acidspecific fluorescent dyes, such as thiazole orange (68).

Reticulated platelets likely represent the youngest platelet fraction. After in vivo biotinylation, freshly formed platelets carrying reduced levels of biotin were shown to be reticulated (69). These platelets are younger than $24 \mathrm{~h}$ (70) and decay their RNA during aging (71).

In healthy humans with steady-state platelet production around $8 \%$ of circulating platelets are reticulated (72). Furthermore, the proportion of reticulated platelets is enriched in the fraction of large platelets compared to the fraction of small platelets (47), suggesting a relationship between platelet size and age.

A limitation of studies applying thiazole orange to stain reticulated platelets is, however, the tendency of this dye to bind unspecifically to alpha-granule contents (73). Therefore, a higher proportion of thiazole orange positive platelets observed in larger platelets could in part result from unspecific binding and may not represent young platelets (74). This limitation may be overcome by more RNA-specific dyes (75), which may finally elucidate the relationship between the size and age of platelets under steadystate platelet production.

In patients with high platelet turnover, the MPV is increased and likewise the proportion of reticulated platelets $(72,76,77)$. One example that these changes may have biological relevance is their response to antiplatelet therapy. Despite dual antiplatelet therapy, large platelets with a higher proportion of reticulated platelets show increased in vitro reactivity compared to small platelets (78). Moreover, newly formed reticulated platelets show increased thrombogenicity after stopping prasugrel (75). Both observations suggest consequences for individualized antiplatelet therapy. 


\section{Procoagulant Platelets}

About $30 \%$ of circulating platelets (range of $15-55 \%$ ) can exhibit a procoagulant phenotype after stimulation with the agonists collagen and thrombin $(79,80)$. They were named COAT-platelets, which was later changed to coated platelets. Coated platelets express high levels of functional $\alpha$-granule derived Factor V (FV) (79) and other $\alpha$-granule proteins on their surface, including fibrinogen, von Willebrand factor, thrombospondin, fibronectin, and $\alpha_{2}$-antiplasmin (81). Furthermore, coated platelets expose procoagulant phosphatidylserine (PS) on their surfaces $(79,82)$. PS exposure on the outer platelet membrane is closely related to disruption of inner mitochondrial membranes in the cells (83). In platelets, this process is controlled by calpain and not by caspases as in other cells (84). Therefore, PS exposure on procoagulant platelets is not necessarily related to apoptosis $(85,86)$. As not all PS-exposing platelets show the typical features of coated platelets, coated platelets seem to represent a procoagulant subgroup of PS-exposing platelets $(82,87)$.

Activation of the protease activated receptor 1 with thrombin, SFLLRN, and AYPGKF had strong additional effect (80) on the collagen-induced calcium peak and induced a sustained cytoplasmatic elevation of $\mathrm{Ca}^{2+}$ which is crucial for the formation of procoagulant platelets (88). Differential phosphorylation of PKCalpha and p38MAPK may drive the different calcium fluxes in coated compared to non-coated platelets (89). Increased cytosolic $\mathrm{Ca}^{2+}$ levels result in the inactivation of adenylatecyclase and activation of phosphatidylinositol 3-kinase and Src tyrosine kinase which further promotes procoagulant platelet segregation (90). On the other hand, elevated cytosolic $\mathrm{Ca}^{2+}$ levels can reverse integrin $\alpha \operatorname{IIb} \beta 3$ activation by stimulating intracellular cleavage of the $\beta 3$-chain via calpain (91). PAC- 1 binding is reduced in coated platelets although surface expression of $\alpha \operatorname{IIb} \beta 3$ is not diminished (89). The underlying mechanism is displacement of PAC-1 a stronger bond rather than inactivation of $\alpha \operatorname{IIb} \beta 3$ (92). This may explain why coated platelets do not take part in the formation of aggregates mediated by $\alpha \operatorname{IIb} \beta 3$.

Thus, platelet subpopulations arrange differently in a thrombus (93). Within a thrombus platelets with activated $\alpha \operatorname{IIb} \beta 3$ integrins assemble to aggregates. Those with inactive $\alpha \operatorname{IIb} \beta 3$ integrins remain solitary and form blebs and shed microparticles (93-95), the typical features of coated platelets. Independently of $\alpha \operatorname{IIb} \beta 3$, coated platelets attach to aggregates by forming caps of colocalized fibrinogen and thrombospondin on the PS-positive platelet surface (96). This allows coated platelets to become incorporated into thrombi independently of activated $\alpha \operatorname{IIb} \beta 3$ integrins.

Interestingly, platelet size has not yet been directly investigated as a feature of procoagulant human platelets. In rabbits, young platelets showed a similar size and the same ability to form procoagulant platelets under steady state compared to older platelets (74). If size is associated with the procoagulant capability of human platelets, it could be applied to enrich or deplete procoagulant platelets in PCs.

\section{Platelets Exposing Signals for Clearance}

Platelets survive for up to 10 days under normal conditions $(97,98)$. Platelets exposing signals to induce their clearance may be seen as another subpopulation with a limited life span. It would be desirable to reduce the amount of these platelets in PCs to prolong survival of transfused platelets.

Three main mechanisms have been identified by which platelets mediate their clearance (99). First, degraded glycans appear as a signal on platelet membranes which are recognized by the hepatic Ashwell Morrel Receptor (100). This has been demonstrated for cold stored platelets (101) and for platelets in sepsis $(102,103)$. Concomitantly, the removal of glycan deprived platelets via the Ashwell Morell Receptor in the liver induces hepatic thrombopoietin-mRNA expression and leads to increased megakaryocyte numbers and de novo platelet production (100).

The second mechanism is platelet apoptosis. Platelet survival is extended if the proapoptotic proteins Bak and Bax are lacking and reduced if the prosurvival proteins $\mathrm{Bcl}-2, \mathrm{Bcl}-\mathrm{xL}$, and $\mathrm{Mcl}-1$ are absent (104). Recently, protein kinase A was identified as a mediator of platelet life span by regulating apoptosis (105). However, the exact signals on the platelet surface and the corresponding receptor recognizing apoptotic platelets for platelet clearance are not yet identified. It is also unknown whether apoptotic signals appear differently in platelets of different size.

Finally, platelets are cleared after being opsonized with antibodies, which can be autoantibodies in diseases such as autoimmune thrombocytopenia, or alloantibodies in case of feto-maternal incompatibility, or after platelet transfusion (106). This mechanism is likely independent of platelet size.

Of note, P-selectin is an adhesion receptor for leukocytes expressed by activated platelets and was suggested to mediate platelet clearance. Berger et al. demonstrated that P-selectin does not mediate platelet clearance but may modulate leukocyte recruitment or thrombus growth (107).

\section{CONCLUSION AND PERSPECTIVES}

Understanding features differentiating platelet subpopulations has greatly improved. For example, platelet size correlates with platelet reactivity and mRNA content, which may classify large platelets as a prohemostatic subpopulation. These large platelets could be enriched in blood centers by differential or density gradient centrifugation, or special apheresis techniques in order to produce more potent PCs, e.g., for trauma patients.

It remains unclear, if large platelet fractions also include more procoagulant platelets. To gain further insight, PS-exposure, $\mathrm{Ca}^{2+}$-mobilization and the ability to form coated platelets should be assessed in large and small platelets. Additionally, no data exist whether immunological functions of platelets correlate with platelet size.

Highly relevant for the interpretation of any study on the association of platelet size and platelet function is the fact that platelet turnover is important for platelet formation. Large platelets under steady state are likely different from large platelets generated under conditions of increased platelet turnover. This difference may explain some of the conflicting results on large and small platelets reported in the literature. It will be mandatory for future studies to exactly define the conditions of platelet turnover under which the investigated platelet population is generated as well as the agonists mediating thrombopoiesis in health and disease (108). 
Platelet turnover may also be relevant for the production of PCs. Platelets derived from whole blood donation are collected under steady-state conditions because the donation procedure routinely lasts $\sim 5-15 \mathrm{~min}$ and will unlikely result in changes in the collected platelets. In contrast, repeated platelet apheresis procedures may stimulate platelet generation because it lowers the platelet content more rapidly over a period of 60-90 min (109) and can be performed up to 3 times a week. This may have an effect on the collected platelet population, as shown for the platelet proteome after repeated apheresis (33). Moreover, platelets collected from hypertensive donors may differ in phenotype and functionality compared to those from normotensive donors (110).

Finally, PCs are produced by differential centrifugation leading to a loss of very large and very small platelets. Recently

\section{REFERENCES}

1. Mancuso ME, Santagostino E. Platelets: much more than bricks in a breached wall. Br J Haematol (2017) 178(2):209-19. doi:10.1111/bjh.14653

2. Morrell CN, Aggrey AA, Chapman LM, Modjeski KL. Emerging roles for platelets as immune and inflammatory cells. Blood (2014) 123(18):2759-67. doi:10.1182/blood-2013-11-462432

3. Cox D, Kerrigan SW, Watson SP. Platelets and the innate immune system: mechanisms of bacterial-induced platelet activation. J Thromb Haemost (2011) 9(6):1097-107. doi:10.1111/j.1538-7836.2011.04264.x

4. Gros A, Ollivier V, Ho-Tin-Noe B. Platelets in inflammation: regulation of leukocyte activities and vascular repair. Front Immunol (2014) 5:678. doi:10.3389/fimmu.2014.00678

5. Hamzeh-CognasseH,Damien P, ChabertA, PozzettoB, CognasseF, GarraudO. Platelets and infections - complex interactions with bacteria. Front Immunol (2015) 6:82. doi:10.3389/fimmu.2015.00082

6. McDonald TP, Odell TT Jr, Gosslee DG. Platelet size in relation to platelet age. Proc Soc Exp Biol Med (1964) 115:684-9. doi:10.3181/00379727-11529006

7. Mezzano D, Hwang K, Catalano P, Aster RH. Evidence that platelet buoyant density, but not size, correlates with platelet age in man. Am J Hematol (1981) 11(1):61-76. doi:10.1002/ajh.2830110108

8. Thompson CB, Love DG, Quinn PG, Valeri CR. Platelet size does not correlate with platelet age. Blood (1983) 62(2):487-94.

9. Agbani EO, Poole AW. Procoagulant platelets: generation, function and therapeutic targeting in thrombosis. Blood (2017) 130(20):2171-79. doi:10.1182/ blood-2017-05-787259

10. Cognasse F, Sut C, Fromont E, Laradi S, Hamzeh-Cognasse H, Garraud O. Platelet soluble CD40-ligand level is associated with transfusion adverse reactions in a mixed threshold-and-hit model. Blood (2017) 130(11):1380-3. doi:10.1182/blood-2017-03-773945

11. Garraud O, Tariket S, Sut C, Haddad A, Aloui C, Chakroun T, et al. Transfusion as an inflammation hit: knowns and unknowns. Front Immunol (2016) 7:534. doi:10.3389/fimmu.2016.00534

12. Chu SG, Becker RC, Berger PB, Bhatt DL, Eikelboom JW, Konkle B, et al. Mean platelet volume as a predictor of cardiovascular risk: a systematic review and meta-analysis. J Thromb Haemost (2010) 8(1):148-56. doi:10.1111/j.1538-7836.2009.03584.x

13. Schick UM, Jain D, Hodonsky CJ, Morrison JV, Davis JP, Brown L, et al. Genome-wide association study of platelet count identifies ancestry-specific loci in Hispanic/Latino Americans. Am J Hum Genet (2016) 98(2):229-42. doi:10.1016/j.ajhg.2015.12.003

14. Soranzo N, Rendon A, Gieger C, Jones CI, Watkins NA, Menzel S, et al. A novel variant on chromosome $7 q 22.3$ associated with mean platelet volume, counts, and function. Blood (2009) 113(16):3831-7. doi:10.1182/ blood-2008-10-184234

15. Nurnberg ST, Rendon A, Smethurst PA, Paul DS, Voss K, Thon JN, et al. A GWAS sequence variant for platelet volume marks an alternative DNM3 it was shown that the preparation procedure of red cell concentrates is associated with mortality (111). Enrichment of a specific platelet subpopulation in PCs by different preparation methods might also be relevant for the outcomes of transfused patients.

In summary, there is increasing evidence on platelet subpopulations with different biological functions, which are particularly interesting for transfusion medicine. Better understanding of the characteristics and functions of platelet subpopulations may be applied to develop new or improved platelet products.

\section{AUTHOR CONTRIBUTIONS}

All authors listed have made a substantial, direct, and intellectual contribution to the work and approved it for publication.

promoter in megakaryocytes near a MEIS1 binding site. Blood (2012) 120(24):4859-68. doi:10.1182/blood-2012-01-401893

16. Shameer K, Denny JC, Ding K, Jouni H, Crosslin DR, de Andrade M, et al. A genome- and phenome-wide association study to identify genetic variants influencing platelet count and volume and their pleiotropic effects. Hum Genet (2014) 133(1):95-109. doi:10.1007/s00439-013-1355-7

17. Li J, Glessner JT, Zhang H, Hou C, Wei Z, Bradfield JP, et al. GWAS of blood cell traits identifies novel associated loci and epistatic interactions in Caucasian and African-American children. Hum Mol Genet (2013) 22(7):1457-64. doi:10.1093/hmg/dds534

18. Gieger C, Radhakrishnan A, Cvejic A, Tang W, Porcu E, Pistis G, et al. New gene functions in megakaryopoiesis and platelet formation. Nature (2011) 480(7376):201-8. doi:10.1038/nature10659

19. De Gabriele G, Penington DG. Regulation of platelet production: "thrombopoietin”. Br J Haematol (1967) 13(2):210-5. doi:10.1111/j.1365-2141.1967. tb08733.x

20. Levin J, Levin FC, Hull DF III, Penington DG. The effects of thrombopoietin on megakaryocyte-cfc, megakaryocytes, and thrombopoiesis: with studies of ploidy and platelet size. Blood (1982) 60(4):989-98.

21. Harker LA, Roskos LK, Marzec UM, Carter RA, Cherry JK, Sundell B, et al. Effects of megakaryocyte growth and development factor on platelet production, platelet life span, and platelet function in healthy human volunteers. Blood (2000) 95(8):2514-22.

22. Patel SR, Hartwig JH, Italiano JE Jr. The biogenesis of platelets from megakaryocyte proplatelets. J Clin Invest (2005) 115(12):3348-54. doi:10.1172/ JCI26891

23. Thon JN, Italiano JE. Platelet formation. Semin Hematol (2010) 47(3):220-6. doi:10.1053/j.seminhematol.2010.03.005

24. DuttingS, Gaits-IacovoniF,StegnerD,PoppM,AntkowiakA,vanEeuwijkJMM, et al. A Cdc42/RhoA regulatory circuit downstream of glycoprotein Ib guides transendothelial platelet biogenesis. Nat Commun (2017) 8:15838. doi:10.1038/ncomms 15838

25. Schwertz H, Koster S, Kahr WH, Michetti N, Kraemer BF, Weitz DA, et al. Anucleate platelets generate progeny. Blood (2010) 115(18):3801-9. doi:10.1182/blood-2009-08-239558

26. Larson MK, Watson SP. Regulation of proplatelet formation and platelet release by integrin alpha IIb beta3. Blood (2006) 108(5):1509-14. doi:10.1182/ blood-2005-11-011957

27. Thon JN, Macleod H, Begonja AJ, Zhu J, Lee KC, Mogilner A, et al. Microtubule and cortical forces determine platelet size during vascular platelet production. Nat Commun (2012) 3:852. doi:10.1038/ncomms1838

28. Stegner D, vanEeuwijk JMM, Angay O, Gorelashvili MG, Semeniak D, Pinnecker J, et al. Thrombopoiesis is spatially regulated by the bone marrow vasculature. Nat Commun (2017) 8(1):127. doi:10.1038/s41467-017-00201-7

29. Machlus KR, Thon JN, Italiano JE Jr. Interpreting the developmental dance of the megakaryocyte: a review of the cellular and molecular processes mediating platelet formation. Br J Haematol (2014) 165(2):227-36. doi:10.1111/ bjh. 12758 
30. Lefrancais E, Ortiz-Munoz G, Caudrillier A, Mallavia B, Liu F, Sayah DM, et al. The lung is a site of platelet biogenesis and a reservoir for haematopoietic progenitors. Nature (2017) 544(7648):105-9. doi:10.1038/nature21706

31. Kowata S, Isogai S, Murai K, Ito S, Tohyama K, Ema M, et al. Platelet demand modulates the type of intravascular protrusion of megakaryocytes in bone marrow. Thromb Haemost (2014) 112(4):743-56. doi:10.1160/TH14-02-0123

32. Nishimura S, Nagasaki M, Kunishima S, Sawaguchi A, Sakata A, Sakaguchi H, et al. IL-1alpha induces thrombopoiesis through megakaryocyte rupture in response to acute platelet needs. J Cell Biol (2015) 209(3):453-66. doi:10.1083/jcb.201410052

33. Thiele T, Braune J, Dhople V,HammerE, ScharfC, Greinacher A, et al. Proteomic profile of platelets during reconstitution of platelet counts after apheresis. Proteomics Clin Appl (2016) 10(8):831-8. doi:10.1002/prca.201500134

34. Thompson CB, Jakubowski JA, Quinn PG, Deykin D, Valeri CR. Platelet size as a determinant of platelet function. J Lab Clin Med (1983) 101(2):205-13.

35. Booyse FM, Rafelson ME Jr. Studies on human platelets. I. Synthesis of platelet protein in a cell-free system. Biochim Biophys Acta (1968) 166(3):689-97. doi:10.1016/0005-2787(68)90376-6

36. Karpatkin S. Heterogeneity of human platelets. I. Metabolic and kinetic evidence suggestive of young and old platelets. J Clin Invest (1969) 48(6): 1073-82. doi:10.1172/JCI106063

37. Karpatkin S. Heterogeneity of human platelets. II. Functional evidence suggestive of young and old platelets. J Clin Invest (1969) 48(6):1083-7. doi:10.1172/JCI106064

38. Karpatkin S, Strick N. Heterogeneity of human platelets. V. Differences in glycolytic and related enzymes with possible relation to platelet age. J Clin Invest (1972) 51(5):1235-43. doi:10.1172/JCI106918

39. Jakubowski JA, Thompson CB, Vaillancourt R, Valeri CR, Deykin D. Arachidonic acid metabolism by platelets of differing size. Br J Haematol (1983) 53(3):503-11. doi:10.1111/j.1365-2141.1983.tb02052.x

40. Mezzano D, Aranda E, Foradori A. Comparative study of size, total protein, fibrinogen and 5-HT content of human and canine platelet density subpopulations. Thromb Haemost (1986) 56(3):288-92.

41. Pereira J, Cretney C, Aster RH. Variation of class I HLA antigen expression among platelet density cohorts: a possible index of platelet age? Blood (1988) 71(2):516-9.

42. Frojmovic M, Wong T. Dynamic measurements of the platelet membrane glycoprotein IIb-IIIa receptor for fibrinogen by flow cytometry. II. Platelet size-dependent subpopulations. Biophys J (1991) 59(4):828-37. doi:10.1016/ S0006-3495(91)82295-0

43. Polanowska-Grabowska R, Raha S, Gear AR. Adhesion efficiency, platelet density and size. Br J Haematol (1992) 82(4):715-20. doi:10.1111/ j.1365-2141.1992.tb06949.x

44. Opper C, Schrumpf E, Gear AR, Wesemann W. Involvement of guanylate cyclase and phosphodiesterases in the functional heterogeneity of human blood platelet subpopulations. Thromb Res (1995) 80(6):461-70. doi:10.1016/0049-3848(95)00201-4

45. Li BY, He SZ, Li WH. Heterogeneity of human platelet density subpopulations in aggregation, secretion of ATP, and cytosolic-free calcium concentration. Zhongguo Yao Li Xue Bao (1996) 17(2):152-5.

46. Opper C, Schuessler G, Kuschel M, Clement HW, Gear AR, Hinsch E, et al. Analysis of GTP-binding proteins, phosphoproteins, and cytosolic calcium in functional heterogeneous human blood platelet subpopulations. Biochem Pharmacol (1997) 54(9):1027-35. doi:10.1016/S0006-2952(97)00317-1

47. Mangalpally KK, Siqueiros-Garcia A, Vaduganathan M, Dong JF, Kleiman NS, Guthikonda S. Platelet activation patterns in platelet size sub-populations: differential responses to aspirin in vitro. JThromb Thrombolysis (2010) 30(3):251-62. doi:10.1007/s11239-010-0489-x

48. Brambilla M, Rossetti L, Zara C, Canzano P, Giesen PLA, Tremoli E, et al. Do methodological differences account for the current controversy on tissue factor expression in platelets? Platelets (2017):1-9. doi:10.1080/09537104. 2017.1327653

49. Balduini CL, Noris P, Spedini P, Belletti S, Zambelli A, Da Prada GA. Relationship between size and thiazole orange fluorescence of platelets in patients undergoing high-dose chemotherapy. Br J Haematol (1999) 106(1):202-7. doi:10.1046/j.1365-2141.1999.01475.x

50. Denis MM, Tolley ND, Bunting M, Schwertz H, Jiang H, Lindemann S, et al. Escaping the nuclear confines: signal-dependent pre-mRNA splicing in anucleate platelets. Cell (2005) 122(3):379-91. doi:10.1016/j.cell.2005.06.015
51. Frojmovic M, Wong $\mathrm{T}$, van de Ven T. Dynamic measurements of the platelet membrane glycoprotein IIb-IIIa receptor for fibrinogen by flow cytometry. I. Methodology, theory and results for two distinct activators. Biophys J (1991) 59(4):815-27. doi:10.1016/S0006-3495(91)82294-9

52. Schwertz H, Tolley ND, Foulks JM, Denis MM, Risenmay BW, Buerke M, et al. Signal-dependent splicing of tissue factor pre-mRNA modulates the thrombogenicity of human platelets. JExp Med (2006) 203(11):2433-40. doi: 10.1084 /jem.20061302

53. Blajchman MA, Senyi AF, Hirsh J, Genton E, George JN. Hemostatic function, survival, and membrane glycoprotein changes in young versus old rabbit platelets. J Clin Invest (1981) 68(5):1289-94. doi:10.1172/JCI110375

54. Adly AA, Ragab IA, Ismail EA, Farahat MM. Evaluation of the immature platelet fraction in the diagnosis and prognosis of childhood immune thrombocytopenia. Platelets (2015) 26(7):645-50. doi:10.3109/09537104. 2014.969220

55. Kaito K, Otsubo H, Usui N, Yoshida M, Tanno J, Kurihara E, et al. Platelet size deviation width, platelet large cell ratio, and mean platelet volume have sufficient sensitivity and specificity in the diagnosis of immune thrombocytopenia. Br J Haematol (2005) 128(5):698-702. doi:10.1111/j.1365-2141. 2004.05357.x

56. Ntaios G, Papadopoulos A, Chatzinikolaou A, Saouli Z, Karalazou P, Kaiafa $G$, et al. Increased values of mean platelet volume and platelet size deviation width may provide a safe positive diagnosis of idiopathic thrombocytopenic purpura. Acta Haematol (2008) 119(3):173-7. doi:10.1159/000135658

57. Bath PM, Butterworth RJ. Platelet size: measurement, physiology and vascular disease. Blood Coagul Fibrinolysis (1996) 7(2):157-61. doi:10.1097/00001721-199603000-00011

58. Freynhofer MK, Gruber SC, Grove EL, Weiss TW, Wojta J, Huber K. Antiplatelet drugs in patients with enhanced platelet turnover: biomarkers versus platelet function testing. Thromb Haemost (2015) 114(3):459-68. doi:10.1160/TH15-02-0179

59. Castle V, Coates G, Kelton JG, Andrew M. 111In-oxine platelet survivals in thrombocytopenic infants. Blood (1987) 70(3):652-6.

60. Lippi G. Genetic and nongenetic determinants of mean platelet volume. Blood (2016) 127(2):179-80. doi:10.1182/blood-2015-11-679852

61. Panova-NoevaM,SchulzA,HermannsMI,Grossmann V,PefaniE,SpronkHM, et al. Sex-specific differences in genetic and nongenetic determinants of mean platelet volume: results from the Gutenberg Health Study. Blood (2016) 127(2):251-9. doi:10.1182/blood-2015-07-660308

62. Montoro-Garcia S, Schindewolf M, Stanford S, Larsen OH, Thiele T. The role of platelets in venous thromboembolism. Semin Thromb Hemost (2016) 42(3):242-51. doi:10.1055/s-0035-1570079

63. Freynhofer MK, Iliev L, Bruno V, Rohla M, Egger F, Weiss TW, et al. Platelet turnover predicts outcome after coronary intervention. Thromb Haemost (2017) 117(5):923-33. doi:10.1160/TH16-10-0785

64. Noris P, Melazzini F, Balduini CL. New roles for mean platelet volume measurement in the clinical practice? Platelets (2016) 27(7):607-12. doi:10.1080/09537104.2016.1224828

65. Eicher JD, Chami N, Kacprowski T, Nomura A, Chen MH, Yanek LR, et al. Platelet-related variants identified by exomechip meta-analysis in 157,293 individuals. Am J Hum Genet (2016) 99(1):40-55. doi:10.1016/j. ajhg.2016.05.005

66. Greinacher A, Pecci A, Kunishima S, Althaus K, Nurden P, Balduini CL, et al. Diagnosis of inherited platelet disorders on a blood smear: a tool to facilitate worldwide diagnosis of platelet disorders. J Thromb Haemost (2017) 15(7):1511-21. doi:10.1111/jth.13729

67. Ingram $\mathrm{M}$, Coopersmith $\mathrm{A}$. Reticulated platelets following acute blood loss. Br J Haematol (1969) 17(3):225-9. doi:10.1111/j.1365-2141.1969. tb01366.x

68. Fujii T, Shimomura T, Fujimoto TT, Kimura A, Fujimura K. A new approach to detect reticulated platelets stained with thiazole orange in thrombocytopenic patients. Thromb Res (2000) 97(6):431-40. doi:10.1016/ S0049-3848(99)00182-6

69. Ault KA, Knowles C. In vivo biotinylation demonstrates that reticulated platelets are the youngest platelets in circulation. Exp Hematol (1995) 23(9):996-1001.

70. Dale GL, Friese P, Hynes LA, Burstein SA. Demonstration that thiazoleorange-positive platelets in the dog are less than 24 hours old. Blood (1995) 85(7):1822-5. 
71. Angenieux C, Maitre B, Eckly A, Lanza F, Gachet C, de la Salle H. Timedependent decay of mRNA and ribosomal RNA during platelet aging and its correlation with translation activity. PLoS One (2016) 11(1):e0148064. doi:10.1371/journal.pone.0148064

72. Kienast J, Schmitz G. Flow cytometric analysis of thiazole orange uptake by platelets: a diagnostic aid in the evaluation of thrombocytopenic disorders. Blood (1990) 75(1):116-21.

73. Robinson M, MacHin S, Mackie I, Harrison P. In vivo biotinylation studies: specificity of labelling of reticulated platelets by thiazole orange and mepacrine. Br J Haematol (2000) 108(4):859-64. doi:10.1046/j.1365-2141.2000. 01939.x

74. Reddy EC, Wang H, Bang KWA, Packham MA, Rand ML. Young steadystate rabbit platelets do not have an enhanced capacity to expose procoagulant phosphatidylserine. Platelets (2017):1-7. doi:10.1080/09537104.2017. 1295434

75. Baaten CC, Veenstra LF, Wetzels R, van Geffen JP, Swieringa F, de Witt SM, et al. Gradual increase in thrombogenicity of juvenile platelets formed upon offset of prasugrel medication. Haematologica (2015) 100(9):1131-8. doi:10.3324/haematol.2014.122457

76. Takubo T, Yamane T, Hino M, Ohta K, Koh KR, Tatsumi N. Clinical significance of simultaneous measurement of reticulated platelets and large platelets in idiopathic thrombocytopenic purpura. Haematologia (2000) 30(3):183-92. doi:10.1163/156855900300109189

77. Salvagno GL, Montagnana M, Degan M, Marradi PL, Ricetti MM, Riolfi P, et al. Evaluation of platelet turnover by flow cytometry. Platelets (2006) 17(3):170-7. doi:10.1080/09537100500437851

78. Guthikonda S, Alviar CL, Vaduganathan M, Arikan M, Tellez A, DeLao T, et al. Role of reticulated platelets and platelet size heterogeneity on platelet activity after dual antiplatelet therapy with aspirin and clopidogrel in patients with stable coronary artery disease. J Am Coll Cardiol (2008) 52(9):743-9. doi:10.1016/j.jacc.2008.05.031

79. Alberio L, Safa O, Clemetson KJ, Esmon CT, Dale GL. Surface expression and functional characterization of alpha-granule factor $\mathrm{V}$ in human platelets: effects of ionophore A23187, thrombin, collagen, and convulxin. Blood (2000) 95(5):1694-702.

80. Prodan CI, Joseph PM, Vincent AS, Dale GL. Coated-platelet levels are influencedbysmoking, aspirin, andselectiveserotoninreuptakeinhibitors.J Thromb Haemost (2007) 5(10):2149-51. doi:10.1111/j.1538-7836.2007.02691.x

81. Dale GL, Friese P, Batar P, Hamilton SF, Reed GL, Jackson KW, et al. Stimulated platelets use serotonin to enhance their retention of procoagulant proteins on the cell surface. Nature (2002) 415(6868):175-9. doi:10.1038/415175a

82. Heemskerk JW, Vuist WM, Feijge MA, Reutelingsperger CP, Lindhout T. Collagen but not fibrinogen surfaces induce bleb formation, exposure of phosphatidylserine, and procoagulant activity of adherent platelets: evidence for regulation by protein tyrosine kinase-dependent $\mathrm{Ca} 2+$ responses. Blood (1997) 90(7):2615-25.

83. Choo HJ, Kholmukhamedov A, Zhou C, Jobe S. Inner mitochondrial membrane disruption links apoptotic and agonist-initiated phosphatidylserine externalization in platelets. Arterioscler Thromb Vasc Biol (2017) 37(8):1503-12. doi:10.1161/ATVBAHA.117.309473

84. Wolf BB, Goldstein JC, Stennicke HR, Beere H, Amarante-Mendes GP, Salvesen GS, et al. Calpain functions in a caspase-independent manner to promote apoptosis-like events during platelet activation. Blood (1999) 94(5):1683-92.

85. Schoenwaelder SM, Yuan Y, Josefsson EC, White MJ, Yao Y, Mason KD, et al. Two distinct pathways regulate platelet phosphatidylserine exposure and procoagulant function. Blood (2009) 114(3):663-6. doi:10.1182/ blood-2009-01-200345

86. Jackson SP, Schoenwaelder SM. Procoagulant platelets: are they necrotic? Blood (2010) 116(12):2011-8. doi:10.1182/blood-2010-01-261669

87. Mattheij NJ, Swieringa F, Mastenbroek TG, Berny-Lang MA, May F, Baaten CC, et al. Coated platelets function in platelet-dependent fibrin formation via integrin alphaIIbbeta3 and transglutaminase factor XIII. Haematologica (2016) 101(4):427-36. doi:10.3324/haematol.2015.131441

88. Keuren JF, Wielders SJ, Ulrichts H, Hackeng T, Heemskerk JW, Deckmyn $\mathrm{H}$, et al. Synergistic effect of thrombin on collagen-induced platelet procoagulant activity is mediated through protease-activated receptor-1. Arterioscler Thromb Vasc Biol (2005) 25(7):1499-505. doi:10.1161/01. ATV.0000167526.31611.f6
89. Alberio L, Ravanat C, Hechler B, Mangin PH, Lanza F, Gachet C. Delayedonset of procoagulant signalling revealed by kinetic analysis of COAT platelet formation. Thromb Haemost (2017) 117(6):1101-14. doi:10.1160/ TH16-09-0711

90. Topalov NN, Kotova YN, Vasilev SA, Panteleev MA. Identification of signal transduction pathways involved in the formation of platelet subpopulations upon activation. Br J Haematol (2012) 157(1):105-15. doi:10.1111/j.1365-2141.2011.09021.x

91. Mattheij NJ, Gilio K, van Kruchten R, Jobe SM, Wieschhaus AJ, Chishti AH, et al. Dual mechanism of integrin alphaIIbbeta3 closure in procoagulant platelets. J Biol Chem (2013) 288(19):13325-36. doi:10.1074/jbc.M112. 428359

92. Szasz R, Dale GL. Thrombospondin and fibrinogen bind serotonin-derivatized proteins on COAT-platelets. Blood (2002) 100(8):2827-31. doi:10.1182/ blood-2002-02-0354

93. Munnix IC, Cosemans JM, Auger JM, Heemskerk JW. Platelet response heterogeneity in thrombus formation. Thromb Haemost (2009) 102(6):1149-56. doi:10.1160/TH09-05-0289

94. Heemskerk JW, Kuijpers MJ, Munnix IC, Siljander PR. Platelet collagen receptors and coagulation. A characteristic platelet response as possible target for antithrombotic treatment. Trends Cardiovasc Med (2005) 15(3):86-92. doi:10.1016/j.tcm.2005.03.003

95. MunnixIC,KuijpersMJ,AugerJ, Thomassen CM,PanizziP,vanZandvoortMA, et al. Segregation of platelet aggregatory and procoagulant microdomains in thrombus formation: regulation by transient integrin activation. Arterioscler Thromb Vasc Biol (2007) 27(11):2484-90. doi:10.1161/ ATVBAHA.107.151100

96. Abaeva AA, Canault M, Kotova YN, Obydennyy SI, Yakimenko AO, Podoplelova NA, et al. Procoagulant platelets form an alpha-granule protein-covered "cap" on their surface that promotes their attachment to aggregates. J Biol Chem (2013) 288(41):29621-32. doi:10.1074/jbc.M113. 474163

97. Mustard JF, Rowsell HC, Murphy EA. Platelet economy (platelet survival and turnover). Br J Haematol (1966) 12(1):1-24. doi:10.1111/j.1365-2141.1966. tb00121.x

98. Najean Y, Ardaillou N, Dresch C. Platelet lifespan. Annu Rev Med (1969) 20:47-62. doi:10.1146/annurev.me.20.020169.000403

99. Grozovsky R, Giannini S, Falet H, Hoffmeister KM. Novel mechanisms of platelet clearance and thrombopoietin regulation. Curr Opin Hematol (2015) 22(5):445-51. doi:10.1097/MOH.0000000000000170

100. Grozovsky R, Begonja AJ, Liu K, Visner G, Hartwig JH, Falet H, et al. The Ashwell-Morell receptor regulates hepatic thrombopoietin production via JAK2-STAT3 signaling. Nat Med (2015) 21(1):47-54. doi:10.1038/ nm. 3770

101. Rumjantseva V, Grewal PK, Wandall HH, Josefsson EC, Sorensen AL, Larson G, et al. Dual roles for hepatic lectin receptors in the clearance of chilled platelets. Nat Med (2009) 15(11):1273-80. doi:10.1038/nm.2030

102. Grewal PK, Aziz PV, Uchiyama S, Rubio GR, Lardone RD, Le D, et al. Inducing host protection in pneumococcal sepsis by preactivation of the Ashwell-Morell receptor. Proc Natl Acad Sci U S A (2013) 110(50):20218-23. doi:10.1073/pnas.1313905110

103. Grewal PK, Uchiyama S, Ditto D, Varki N, Le DT, Nizet V, et al. The Ashwell receptor mitigates the lethal coagulopathy of sepsis. Nat Med (2008) 14(6):648-55. doi:10.1038/nm1760

104. Mason KD, Carpinelli MR, Fletcher JI, Collinge JE, Hilton AA, Ellis S, et al. Programmed anuclear cell death delimits platelet life span. Cell (2007) 128(6):1173-86. doi:10.1016/j.cell.2007.01.037

105. Zhao L, Liu J, He C, Yan R, Zhou K, Cui Q, et al. Protein kinase A determines platelet life span and survival by regulating apoptosis. J Clin Invest (2017) 127(12):4338-51. doi:10.1172/JCI95109

106. Curtis BR, McFarland JG. Human platelet antigens - 2013. Vox Sang (2014) 106(2):93-102. doi:10.1111/vox.12085

107. Berger G, Hartwell DW, Wagner DD. P-Selectin and platelet clearance. Blood (1998) 92(11):4446-52.

108. Alberio L. Do we need antiplatelet therapy in thrombocytosis? Pro. Diagnostic and pathophysiologic considerations for a treatment choice. Hamostaseologie (2016) 36(4):227-40. doi:10.5482/HAMO-14-11-0074

109. Heuft HG, Moog R, Fischer EG, Zingsem J. German, Austrian Plateletpheresis Study G. Donor safety in triple plateletpheresis: results from the German and 
Austrian Plateletpheresis Study Group multicenter trial. Transfusion (2013) 53(1):211-20. doi:10.1111/j.1537-2995.2012.03714.x

110. Gebhard S, Steil L, Peters B, Gesell-Salazar M, Hammer E, Kuttler B, et al. Angiotensin II-dependent hypertension causes reversible changes in the platelet proteome. JHypertens (2011) 29(11):2126-37. doi:10.1097/ HJH.0b013e32834b1991

111. Heddle NM, Arnold DM, Acker JP, Liu Y, Barty RL, Eikelboom JW, et al. Red blood cell processing methods and in-hospital mortality: a transfusion registry cohort study. Lancet Haematol (2016) 3(5):e246-54. doi:10.1016/ S2352-3026(16)00020-X
Conflict of Interest Statement: The authors declare that the research was conducted in the absence of any commercial or financial relationships that could be construed as a potential conflict of interest.

Copyright (®) 2018 Handtke, Steil, Greinacher and Thiele. This is an open-access article distributed under the terms of the Creative Commons Attribution License (CC $B Y)$. The use, distribution or reproduction in other forums is permitted, provided the original author(s) and the copyright owner are credited and that the original publication in this journal is cited, in accordance with accepted academic practice. No use, distribution or reproduction is permitted which does not comply with these terms. 